nating power, and the resulting seedlings show a greater power of resistance against external injurious influences, and a more vigorous development, which in many species is due to the greater quantity of reserve materials deposited in the seed. This superiority at the first start should not be underestimated; because it is recognizable long after the seedling stage has been passed. In many cases the dominating trees grow out of seedlings which had the best start."

At another point in discussing the source of seed he says: "The source whence seed has been obtained is of importance. Although trees of all ages can yield excellent seed, as a general rule it may be said that the best seed is derived from trees which are in the prime of life, namely. healthy trees with a full crown, which have just completed their principal height growth. At the same time, soil and climate, especially the latter, are of greater importance than the age of the trees.

"The question has been raised whether it may be advantageous to obtain from time to time seed from another locality, as is done in agriculture. This may become desirable when the trees are affected by disease or by peculiarities which are transmitted through seed, as for instance, twisted fiber; apart from such cases, it is probably better not to change the seed. Trees live for a long space of time, and they accommodate themselves to a locality, so that home seed is likely to do best."

\title{
REPORT OF COMMITTEE ON BREEDING FORAGE PLANTS.
}

By Prof. J. H. ShePPERd, Fargo, N. Dak.

As chairman of your committee on breeding forage plants, I wish to explain that the report which I submit herewith may not represent the ideas of the committee as a whole. There seemed to be a strong probability that a majority of the committee would be able to meet for a personal conference during the fall months and I delayed correspondence with the thought that I would be able to confer much more satisfactorily after the proposed meeting. Later on it was found impossible to effect a meeting of the committee, and, a number of: unexpected duties falling to the lot of the chairman, he was unable to take up the matter with the members of the committee until so late a date that the final report as compiled could not be returned to them for revision, criticism, and sanction.

The more intense nursery method of breeding forage crops has not been generally taken up so promptly as the work with grains, although the worthy secretary of this organization spent considerable time and effort upon the timothy plant in a strictly nursery way nearly twenty years ago and left the writer a heritage in the form of a timothy plant nursery at Fargo in 1893.

Garton Brothers, of England, have for many years given to the world an example of successful work in nursery forage plant breeding.

American experiment stations have, however, worked out the preliminary and fundamental basis for nursery or individual plant work by studying cultural methods and the adaptation of standard and introduced sorts to particular districts. Cornell University Station, for example, has made a study of the relative production of the differ- 
ent grasses, the relative palatability, the influence of mixtures in reducing the number of weeds, the influence of fertilizers and the development and duration of various species of grasses and clovers. The Cornell Station has carried on experiments to determine what is necessary to succeed with alfalfa on soil confessedly not adapted to this plant. They have learned that on Dunkirk clay loam three things are essential to succéssful alfalfa culture; manuring the land with stable manure, the application of lime, and the use of soil from other alfalfa fields. These experiments have shown that with this soil type, no two of the conditions named are sufficient for successful alfalfa culture. The above described trial is being followed by plant nursery work as a natural consequence, and, of course, with much better chance of success than though the preliminary work had not been done.

The work of the Northwestern State stations has dwelt much longer upon preliminary trials than is necessary in the older districts as the country is new and not adapted to the old line of cultivated strains. Ten years of work were necessary to learn the cultural requirements and natural adaptation of that peculiar but ultra-useful Plains plant, Brome grass, and much still remains to be done in that direction. The North Dakota Station has spent more than a decade upon a native forage plant-Slender Wheat Grass-(Agropyron tenerum) and has succeeded in adapting cultivation and farm handling methods to it in such form as to make it a standard grass for that section. All of this is preliminary and essential foundation work for plant breeding; and, while it is to be regretted that nursery-plant breeding was not carried on at the same time, let us congratulate ourselves upon the fact that the work has really been in progress much longer than we are frequently wont to reckon.

Forage-plant breeding resolves itself into six features or lines for experimentation.

1st. A study of the forage plants adapted to a given district and those which can be grown economically by the producer.

2d. The cultural methods adapted to each particular sort such as the best date and thickness of seeding, preparation of the seed bed, depth best adapted, the degree of success attained with and without a nurse crop, the supply of fertility and of humus required, and various features of alkalinity and bacterial inoculation. Many of these points are already known from the common experience of the forage producers of the district, but they prove serious and frequently thwart effort when not taken into account and worked out as fundamental and pre-requisite preliminary studies. Some most excellent native grasses of the Plains, for example, seed very sparingly, which makes the reproduction of them in a field way so expensive as to prove prohibitive to their use as cultivated crops.

3d. Plant nursery selection which ramifies into many details of work according to whether the individual plants are studied in detail as to the number of stools produced, diameter of the stems, number of 
leaves per culm, flavor and odor, the chemical features, such as crude fiber when of pasture size and age, crude fiber when heading, when in blossom, when the bloom has fallen and when in the milk, dough, glazing, and ripe stages of the seed. In like manner the protein, nitrogen-free extract, and ether extract are features of interest and present useful fields for research work. After the successful strains are increased comes the question of the quantity of each refused by. the different classes of live-stock and the composition of the part rejected.

4th. Cross fertilization presents a promising and fascinating field for operation among forage plants, giving wide variations in type, hardiness, quality and in fact in every useful feature. Now that vegetative reproduction is successfully practiced this field of work and that of hybridization are made much more probable producers of results than could otherwise have been expected.

5th. Hybridization is an almost wholly open field for work with forage plants and one which-reasoning upon principle and analogymust prove of great service in producing the proverbial two blades of grass where one grew before.

6th. The production of hardy strains as measured (a) by wet swampy conditions; (b) by uniformly dry seasonal districts; (c) by climates subject to drought during certain portions of the season; (d) by the presence of alkali salts; (e) by other climatic conditions such as the degree of humidity of the air.

With all of these conditions and climatic helps the investigator can usually make rapid strides with introduced forage plants until approximate equilibrium is reached after which either an intense condition, such as strong alkalinity or the plant-breeding methods which induce variation must be relied upon for still further improvement.

In the last two or three years important results have been obtained by a number of experimenters-the following being some which have come under the immediate observation of one of the members of your committee: (1) Results from work upon timothy by Hopkins in West Virginia; (2) with certain grasses by Burbank in California; (3) with a series of leguminous forage plants and grasses by W. A. Wheeler in South Dakota; and (4) with sorghum varieties in northern Texas by A. H. Leidigh, and A. B. Conner, of the Bureau of Plant Industry. This probably represents a mere fraction of the work carried out by all investigators with forage crops.

Methods of breeding are not yet as highly developed as in the case of such staple crops as wheat, corn, and cotton; and the problem of determining which are the best individual plants of alfalfa, red clover, or timothy, for example, is not always an easy one. Judging the value of variations in these crops is by no means a simple matter, for the characteristics of individuals have not been studied as closely as in other crop plants. Simple selection has so far been the method principally followed in this country, although the striking results with cowpeas and other forage plants recently obtained by Oliver, of the Bureau of Plant Industry, show what can be obtained by judicious crossing. 
The methods do not differ in any important respect from those followed with most field crops. The first selections can be made from such fields of the crop in band as the breeder finds in his neighborhood, or from small plats that have been seeded for the purpose. The former method is probably preferable in most cases, as a larger number of plants are available and there is a better chance of securing hardy individuals, capable of good development under more or less unfavorable conditions. In whatever way obtained, the seed of the selected plants of each strain or variety is then to be sown in small breeding plats, the progeny of each individual being given a separate row or fraction of a row. The plats should, of course, be as uniform as possible with regard to soil texture, drainage, etc., in order that variations due to differences in the environment may be as far as possible eliminated. What we should have is, of course, a perfectly fair comparison of the individual plants and this can only be had by perfect uniformity of the conditions. In the case of most forage crops it is necessary to thin out the rows after the seedlings are up, so as to leave room for each plant to attain its full development without being crowded. This is especially important where free stooling is desired or where capacity for seed production is given especial attention. It should be remembered, however, that the progeny of individuals that are best and most productive under these experimental conditions will not necessarily give the largest yields when sown in the field under ordinary cultural conditions. The final test of any strain thus obtained must be its performance when grown in the usual manner.

Where rapid propagation from one or a few selected individuals is desirable, the method followed by Hopkins with timothy, that of transplanting rooted suckers from the parent, is to be recommended, when working with grasses that have the habit of stooling. Oliver has recently perfected a method of vegetative propagation of forage crops which consists in cutting off the upper part of the stem and rooting it in sand. In this way he has been able in one season to secure thousands of thrifty individuals from a single plant of alfalfa. Mr. Oliver believes that this method can be used with all herbaceous dicotyledons. With monocotyledons it is less satisfactory, although good results have been attained in rooting the young leafy shoots of oats.

Where resistance to cold, drought, alkali, or disease is the main object, nature cooperates with the breeder to the extent of doing a large part of his work and it becomes necessary to select only the best of such plants as survive these strenuous conditions. In such cases the breeder is generally well pleased to obtain a strain of only fair quality and productiveness, provided it is strikingly resistant. But where the conditions are entirely favorable to the crop and it is simply a question of securing an improvement in yield or quality much closer attention to the individual characters and greater degree of judgment are demanded. Careful counts of the number of stalks, number of leaves to the stalk, height, size and texture of leaves, etc., as well as careful weighings of green and dry yields are in order. Comparative chemi- 
cal analyses and feeding tests are also desirable, before the strain is offered to the public. Little attention has been paid to the comparative composition and feeding value of slightly different strains of the same forage crop, but there is good reason to believe that this side of the work should not be neglected.

Mr. Kearney, a member of this committee, has had in charge for some years, the work of the Department of Agriculture in testing crops with regard to their resistance to alkali, with a view to securing useful plants that can be grown on the large bodies of alkali soil that occur in the Western States. Resistant plants have been sought, not only in this country, but in other parts of the world. Especial attention has been paid to alfalfa and other forage crops and it has been found that great differences exist in the ability to withstand alkali, not only between different species or varieties, but between different individuals of the same species or variety, some being able to ripen seed in three or four times as much alkali as others can endure. Carefully selected pieces of alkali land are used as breeding plats and the usual breeding methods are followed. Heretofore great difficulty has been encountered in the selection of land for this purpose, since the amount of alkali fluctuates greatly during the season, following the movements of the soil water. This difficulty is, however, being overcome with experience. During the coming season work of this nature will be carried on at North Platte, Nebraska (in cooperation with the State Experiment Station), at Fallon, Nevada, and at Yuma, Arizona.

\section{REPORT OF COMMITTEE ON BREEDING BEES AND OTHER INSECTS.}

By Dr. L. O. HowARD, Chairman, Bureau of Entomology, U. S. Department of Agriculture.

The work of this committee during the past year has been necessarily limited. The attention of bee keepers has been called to the Association through the agricultural press in articles by two members of the committee and by references to it in addresses to various bee keepers' societies by Dr. E. F. Phillips, of the Bureau of Entomology.

Since the principles involved in breeding bees for improvement are practically the same as those employed by other breeders, it has seemed best, as a preliminary step, to call the attention of the persons interested in bee breeding to what has been accomplished in other lines of work. In addition to this, several cases have come to the notice of the committee where some peculiar results have been obtained and an' effort is being made to find out the means employed. Attention. will be called to this at a future time.

Mr. J. P. Moore, of Morgan, Ky., a member of this committee, and 